\title{
Aisthesis
}

Firenze University Press

www.fupress.com/aisthesis

OPEN ACCESS

Citation: F. Desideri (2021) Labyrinth, Ruin, Junkspace, Monad: dialectical images of the contemporary city. Aisthesis 14(2): 101-109. doi: 10.36253/Aisthesis-13213

Copyright: (c) $2021 \mathrm{~F}$. Desideri. This is an open access, peer-reviewed article published by Firenze University Press (http://www.fupress.com/aisthesis) and distributed under the terms of the Creative Commons Attribution License, which permits unrestricted use, distribution, and reproduction in any medium, provided the original author and source are credited.

Data Availability Statement: All relevant data are within the paper and its Supporting Information files.

Competing Interests: The authors have declared that no competing interests exist.

\section{Labyrinth, Ruin, Junkspace, Monad: dialectical images of the contemporary city ${ }^{1}$}

\author{
FABRIZIO DESIDERI \\ University of Florence (Italy) \\ fabrizio.desideri@unifi.it
}

\begin{abstract}
The theoretical presupposition of the discourse developed here is Benjamin's conception of a dialectical image applied to the experience of the modern and contemporary city. The starting point is that of the radical strangeness between the inner life of the individual and the time of the modern metropolis. In this regard, we compare some verses taken from the third book of the Stundenbuch by Rainer Maria Rilke and Georg Simmel's essay, Die Großstädte und das geistiges Leben, at the center of which is the Nervenleben as an intensification of the perceptive life typical of the experience of the modern city. We then move on to focus on the theme of the labyrinth analyzed by Benjamin in some passages of the Passagenwerk. In this regard, it is emphasized how the modern city realizes the ancient dream of the labyrinth elevating it to the sphere of language. The experience of the city as a labyrinth is interpreted as a «monotonous wandering», which is not delayed in a senseless roaming. In conclusion, the image of the Generic City and of the Junkspace theorized by Rem Koolhaas is compared, as an image that describes our present in the interweaving of the virtual city of cyberspace with the real city, as an alternative image to that of monad. As a monad, the image of the city still reserves the possibility of experiencing the truth, in a paradoxical gaze that captures the original idea of the city from the inside. This confirms that in the connection between city and monad already underlined by Leibniz "the true has no windows", according to one of the most esoteric passages of the Passagenwerk.
\end{abstract}

Keywords: Modern and contemporary city; Rainer Maria Rilke, Georg Simmel, Walter Benjamin, Rem Koolhaas, dialectical images, ruin, Labyrinth, Junkspace, Generic city, Monad.

In Benjamin's notion of a dialectical image coexist two instances, the anarchically irreducible one of the images in their not conceptual presentation and the ordered one of synthesis capable of conferring historical depth to the materials represented. The being of a certain image in those authentically historical objects which are the

\footnotetext{
${ }^{1}$ Here I publish the text of the Conference held on November 5 for the activities of the research group "Projecto Experiéncia da Cidade" coordinated at the Universidade Nova in Lisbon by Prof. Filomena Molder and Prof. Nélio Conceição. I thank the organizers for this wonderful opportunity.
} 
"dialectical images» exists first of all as an expression of historical phenomena, such as the passages, the streets of Paris, the commodities in the shop windows, the prostitutes etc., phenomena that concern us, as if they casted us an alienating glance in the form of clues and suggestions waiting to be grasped by thought. On that moment in which the image can deny itself, almost disappearing, to resurrect dialectically to a new life. As a dialectic, the image is thus transformed into an authentically historical object whose truth can be known in the catastrophic intermittences of the Jetzt-Zeit.

In the passage between its first appearance, its first historical-temporal appearance and its transformation into a dialectical image, the historical phenomenon, in the radical contingency of its origin, already has the character of ruin. As Benjamin perfectly understands about the passages, considering them as monuments of memory, persistent remains of something that is no longer:

Being past, being no more, is passionately at work in things. To the historian trusts for his subject matter. He depends on this force, and knows things as they are at the moment of their ceasing to be. Arcades are such monuments of being-no-more. And the energy that works in them is dialectics. The dialectic takes its way through the arcades, ransacking them, revolutionizing them, turns them upside down and inside out, converting them, since they no longer remain what are, from abodes of luxury to $\langle x\rangle$. And nothing of them lasts except the name: Passages. And: Passage du Panorama $<$ sic > (Benjamin [2002a]: 833)

Through the filter of the name, through the language that - as we shall see - lies in intimate correlation with the city, the passages as a ruin that attests the restlessness of their non-being, assume the character of dialectical images and this allows us to consider dialectically, by virtue of the micrological arrangement that marks Benjamin's thought, the very image of the modern metropolis. The first image through which the modern metropolis, as a fusion in its origin between the city of consumers and that of producers at the center of the fundamental Weberian analysis, offers itself to thought is, however, a not-dialectical image, with respect to which the constitutive elements of every experience are dissociated, to the point of witnessing that trait of irreconcilability ready to pass into a hostile strangeness.

1. If we disregard some anticipations contained in Nietzsche's Zarathustra, the sense of a radical estrangement from the modern metropolis is expressed in the words of poetry, rather than those of philosophy. Here I am thinking to some verses of the Third Book of the Stundenbuch by Rainer Maria Rilke, entitled Von der Armut und vom Tode. We are at the time when Rilke goes to Paris in the name of Rodin, and it is on this occasion - as the letters to Lou von Salomè in the summer of 1903 attest - that Rilke's experience of a Paris already filtered through the reading of the Tableaux Parisiens is that of an absolute strangeness. It is an experience characterized by a "distressing astonishment" because of which the same anguish of the poet from the dimensions of a "remote village» takes on that of «a city, a large city in which the unspeakable happens» (Letter to Lou dated July 18, 1903 cited in Rilke [1994]: V. II, 786-788). The words contained in the letter to Lou of July 1903 converge in condensing the relationship with Paris and with the modern metropolis in general in the sense of a tormented poverty where the soul becomes a speculum, a counter-image, a reflection of the monstrous excess of the city that sows dismay in its inhabitants. The radical strangeness and misery of the metropolitan experience return in the Rilkian verses:

Die großen Städte sind nicht wahr; sie täuschen / den Tag, die Nacht, die Tiere und das Kind. (Rilke [1994]: V. II, 250)

[The big cities are not true; they deceive / the day, the night, the animals and the child.]

\section{Their silence lies:}

Nichts von dem weiten wirklichen Geschehen, / das sich um dich, du Werdender, bewegt, / geschieht in ihnen [...] (Ibidem) 
[Nothing of the broad actual happening that moves around you, to you as you become, happens in them].

What dominates is the split between the poet's self, the universal voice of everyone, and the lying time of the city: the latter's happening is different from what happens in the soul. A disordered and insatiable expansion is opposed to the composition of an inner growth. Another, radically and threateningly different is the logic that cities obey in their becoming that is one with the ravenously destructive fury of time:

Die Städte aber wollen nur das Ihre / und reißen alles in ihren Lauf. (Rilke [1994]: V. II, 268)

[The cities, however, only want theirs / and tear everything in their course].

An autonomous form is therefore that of the modern city which imposes itself with the force of a second wild nature that overwhelms everything. The rhythm and telos of its transformations, which enslaves its inhabitants without balance and measure, is that dictated by money that "grows and sucks all energy" with the force of a devastating wind., Similar here to the storm called progress of the Benjaminian Theses on the concept of history. And of all this, Rilke observes, above all his poor suffer, driven from every home, «like strangers who wander in the night».

The city, therefore, as a space for a desolate wandering and dispersion. For this reason, the image that the city gives here represents the perfect antithesis to that of the labyrinth, where getting lost, wandering always nourishes the hope of finding oneself grasping the right thread that leads to the goal. If we were to find a philosophical counterpoint to Rilke's poetic word around that experience of the modern metropolis of which Paris offers the most eloquent emblem even literally, we should look at Georg Simmel's contemporary essay, Die Großstädte und das geistiges Leben, perhaps - together with the one on Fashion - the most masterfully expressive essay on the fundamental analyzes of the dynamics of the Modern represented by great works such as the Philosophie des Geldes (1900) and Soziologie (1908). Compared to the terrified Rilkian experience, the lucid and disenchanted Symmelian diagnosis can be considered as completely complementary. Where in Rilke dominates the Stimmung of anguish that becomes a city to reflect the perverse self-finalism of an artificial formation, of a machine that «only wants its own» and, like money, grows without measure, sucking up every other energy, in Simmel the dominant Stimmung of the life of the metropolis and of the atmosphere that surrounds it is the Nervenleben: "the intensification of the nervous life» (Simmel [1995]: 116 [this and other translations by Simmel are by the author]) determined by the inexhaustible alternation of external and internal impressions.

To the falsehood of the experience of the city of which Rilke speaks, to its frightening shrinking and impoverishing, corresponds for Simmel the fading of the diaphragm that separates the external convulsion and the intimacy of the interior. By virtue of this loss of the protective threshold between inside and outside, due to the intensification and expansion of a pure Nervenleben, the metropolitan psychic life - observes Simmel withdraws into the intellect, as more adaptable to upheavals than pure sentiment. would not be able to bear. Only pure intellect, in the secession from traditional identity anchors and more generally from the constraints of feeling, can correspond to the dominance of the money-form, as an empty symbol that has sucked up every other symbolic form, emptying it from the inside. In both cases: in pure intellectualism and in the empty and powerful symbolism of money (pure functional relationship elected as absolute $)^{2}$ one is perfectly indifferent to what is rooted in life with the stamp of individual quality. Logic of quantity, one in which intellect and money substantially converge, celebrating the power of hyper-functionalism and the resolution of any value to pure exchange value.

As constituted in the abstract circle between production and consumption, the modern city

\footnotetext{
${ }^{2}$ On the crucial theme for Simmel of money as a pure symbol (as a relationship of relationships) and its ontological value, see Desideri [2020].
} 
identifies its space-time and its own image in the market as the soul of the very social life of individuals whose subject is the commodity-form and its purest and most effective symbol: money as a relationship of relationships. To the extent that the secessionist functionalism of the intellect is not only congenital with this symbolic form but coevolves with it. Thus, we celebrate a fundamental and constitutive aspect of the modern general intellect that reduces everything to calculation, transposing every qualitative value into measurable and negotiable quantitative value. Of this spirit the metropolis is cause and effect at the same time. Common to both is a superindividual structure of time that sucks into itself every inner rhythm of the individuum. Hence, Simmel explains, the hate of Ruskin and Nietzsche for the metropolis. In harmony with this time of the calculating impersonal (in the homology between the abstraction of the intellect and the moneyform), only the blasé can be the one who has metabolized the thickening in rapid succession of the nervous stimulations to which every inhabitant of the metropolis is subjected. To the point of developing an extreme indifference of feeling or, at least, the ability to muffle the sensitivity for the differences. Everything for the blasé becomes colorless, gray - money as a terrible leveler «empties without escape the core of things, their particularity, their individual value, their incomparability » (Simmel [1995]: 122). The inner side of this condition of feeling is, on the level of human relations, the sense of a "tacit aversion», of a «mutual extraneousness» (Ivi: 123): that of which Rilke speaks in poetic consonance with the Simmelian theses.

The concluding words of Simmel's essay concern the shape of the modern metropolis as a "functional quantity that transcends its physical frontiers" (Ivi: 127) . Before considering the relationship between this image of the market-city governed by the calculating abstraction of the general intellect with the hyperreal city constituted by the digital network with its taking root in physical points of access and connection, we must ask ourselves whether it is possible or not, within these physical as well as metaphysical frontiers, to experience another image of the modern city. In summary, an image of it different from the undialectical and all-encompassing one described so far.

The positive answer to this question depends on the fact that an experience of the modern metropolis as a labyrinth is still possible. An experience, that is, where wandering is not absolute up to the indifference of the steps one takes but is still a search. In light of the contemporary metamorphosis of our metropolises, captured on the one hand by the pure formless (by an accumulating excess) and on the other exhibited and experienced in mass tourism as a carnivalesque and often sinister parody of their original idea, Benjamin's thought, especially in the complex of writings belonging to the Passagenwerk, confirms his prophetic farsightedness: his telescopage into the future, beyond the catastrophes and the cloud of blood of historical destruction.

2. When Benjamin speaks of the labyrinth character of the modern metropolis, he does not think only of the flâneur as a border figure of 19th century Paris, even though the fate of the flâneur is entirely intrinsic to this image, delivering himself to the past at the very moment in which his idle wandering crosses the threshold of the market. In any case, the Paris of the passages does not immediately offer itself as a labyrinth on the horizontal plane of its streets and boulevards. It offers itself as a labyrinth, rather, through the complex weaving of references and intersections between the underground network of the Metro and the linguistic facies with which the city presents itself. In short: only through the filter of language can the experience of the modern metropolis become the experience of a labyrinth. The reason for this as shown by Benjamin's brief but decisive notes on the subject - lies in the historical and conceptual connection that is determined between two equally distinctive ideas of the human: that of architecture and that of consciousness. Only in this welding - observes Benjamin - the city becomes "the realization of that ancient dream of humanity, the labyrinth" (Benjamin [2002a]: 429). 
The labyrinth of urban dwellings - observes Benjamin in another passage - "by day [...] resembles consciousness" (Benjamin [2002a]: 875) and the passages in this context represent the openings that lead into the past existence of the city ("in ihr vergangenes Dasein"). While during the day "the arcades [...] issue unremarked into the street" is "at night, however, under the tenebrous mass of the houses" that "their denser darkness protrudes like a threat" (Ibidem). Only by venturing into the nocturnal side of those that in the sunlight seem nothing more than passages, places of transit, does the city give back the experience of a labyrinth: an experience that as such has the connotations of risk and threat. Those same connotations that - unraveling the thread of a necessary metaphorization - the experience of consciousness assumes when thought ventures into the stratified darkness of its past, exploring its endless entanglements. In summary: there is experience as much of the labyrinth of the modern metropolis as of that of consciousness, provided that the chthonic side is considered in both cases, not as an accessory and contingent characteristic, but constitutive. Thus, the consciousness, in addition to that of a labyrinthine depth, will be able to incorporate the image of the threshold.

Only on this condition, "in the labyrinth of the city" does the experience of consciousness discover "the newest and most inscrutable Labyrinth" (Benjamin [2002a]: 446): that of the mass, as the trait of an indistinct plurality that constitutes the reverse of individual identity. In fact, it is through the mass that "previously unknown chthonic traits are imprinted on the image of the city" (Ibidem) and through this image they can reflect themselves in consciousness itself, as a dark background of its knowledge and its knowing itself. The mass, in fact, as a veil that stands in the way of the return to itself in that constant hesitation that marks the wandering of the flâneur and is assumed as a "drug for the solitary" precisely because it cancels in itself "all traces of individual" (Ibidem).

Between the hesitant strangeness of the single individual, exemplified by the flaneur, and the undifferentiating character of the mass, those extremes that we had encountered in a virtual comparison between the poetic word of Rilke and the philosophical one of Simmel seem to recur. Between these extremes, however, in Benjamin's analysis there is an immaterial and concrete bridge at the same time: that of language.

"What the big city of modern times has made of the ancient conception of the Labyrinth?" (Benjamin [2002a]: 839) - is the question Benjamin answers by identifying in language the medium of the modern transformation of an archaic image for human consciousness, an image that borders on the dream: "It [the big city of modern times) has raised it [the ancient conception of the labyrinth], through the names of streets, into the sphere of language, raised it from out the network of streets» which by virtue of their names assume a linguistic existence.

Only through the filter of language as a network and the names that make up its nodes does it still become possible, in the tension between the residual power of the archaic and forms of modern existence, to experience the city as a labyrinth. By signaling with their red lights the entrance to the labyrinthine underground network of the Métro, the names of the streets seem to regain something of their original symbolic power. Street names, in the city-language, become literally expressive again, manifesting a silent and evocative dialectic between exterior and interior.

Through the filter of the names considered in the naked and alienated existence that they assume in the undergrounds of the Métro, once freed from the "the collision, the intersection, of names-that which aboveground forms the linguistic network of the city" (Benjamin [2002a]: 84), the experience of the labyrinth finds its fulfillment, the realization of an idea or an ancient dream where the steps taken, each path and the pure and simple walking is not separate from wandering. Wandering, getting lost in knowing it, requires experience and foresight, as Benjamin does not fail to observe in a famous passage from Berliner Kindheit:

Not to find one's way around a city does not mean much. But to lose one's way in a city, as one loses 
one's way in a forest, requires some schooling. Street names must speak to the urban wanderer like the snapping of dry twigs, and little streets in the heart of the city must reflect the times of day, for him, as clearly as a mountain valley. This art I acquired rather late in life; it fulfilled a dream, of which the first traces were labyrinths on the blotting papers in my school notebooks. (Benjamin [2002b]: 352)

Getting lost in a city like in a forest is an art, because it presupposes that one's wandering, one's own progress with interruptions and as if left to chance, follows a thread, follows it while weaving it. For this reason, wandering in the paths of a labyrinth is never an absolute getting lost, to the same extent that in this same space the way cannot be direct. Hence the similarity between the mythical figure of the labyrinth and the one of consciousness. And experience of consciousness, up to the ability to self-reflect in knowledge, as $\mathrm{Hegel}^{3}$ teaches, can only be given in the medium of language (even if it is not resolved in this medium).

On the other hand, only through this passage it is possible to give experience "in the strict sense" that is as an authentic Erfahren in the interpenetration of exterior and interior, of the dimension of the street and of the interieur, of contents of the individual past with contents of the collective one. Experienced as a labyrinth, by virtue, so to speak, of the metabolization of its scheme, the modern city acquires historical depth, by resurfacing the strata of the past that overlap in it. As a dialectical image, the labyrinth therefore joins not only the archaic and recent history (die Moderne) but helps to re-tie the strings between aspects and dimensions of the past with critical protrusions of the present. Thus, as a continuous excursus between different temporal planes, labyrinthine becomes not only the space of the city, but also time. However, it would be a mistake to resolve the two dimensions into pure dispersion and loss of orientation. Essential to the figure

\footnotetext{
${ }^{3}$ On Benjamin's relationship with Hegel in relation to the Passagenwerk see my recent essay, Dialektik im Stillstand. Prolegomeni ad un confronto tra Benjamin e Hegel (Desideri [2021]).
}

of the labyrinth is neither the possession of the center nor its absence, but rather the need to look for it. Through the filter of language as a medium of experience in the strict sense, this research becomes a question. Here the Passagenwerk connects to the book on the Trauerspiel, attesting an extraordinary continuity in Benjamin's philosophy. In fact, names are questioned and listened to as a filter that has retained the essence of what is no more. And the first name to question is precisely that of the passages:

The inner radiance of the arcades faded with the blaze of electric lights and withdrew into their names. But their name was now like a filter which let through only the most intimate, the bitter essence of what had been. (Benjamin [2002a]: 834)

If this passage is already illuminating in itself for a consideration of the labyrinth as a dialectical image of the modern city, the gloss that Benjamin adds in parentheses is even more so:

This strange capacity for distilling the present, as inmost essence of what has been, is, for true travelers, what gives to the name its exciting and mysterious potency. (Ibidem)

The nature of the "true traveler" is not alien to that of those who venture into the city by getting lost, but as if he were moving in a labyrinth. The center or the goal, albeit with the shape of a ghost, are nevertheless present in this wandering, in this alienation, where the conscience is confronted with the otherness: with something other than itself. They are perhaps so as a negative condition, an impossible possibility by virtue of which those who err can be reunited with themselves, even if only in the form of a con-scientia, of a knowledge that has the flavor of awakening.

This is the moment of awakening which coincides with grasping the dialectical images as a historically authentic synthesis between past and present, between memory and oblivion: a synthesis whose essence is hidden in the names as a latent life that waits to unfold for an intelligent listening capable of questioning them. In this dialectic 
figure, the "awakening" constitutes the synthesis between "dream consciousness" and "waking consciousness" (Benjamin [2002a]:858): unstable threshold, intermittent passage between the two dimensions.

To the same extent that awakening is a dialectical synthesis, so is that dimension of the labyrinth that is elevated to the sphere of language. In fact, in the image of labyrinth are merged both the mythological nature of the "way", which implies "the terrors of wandering, some reverberation of which must have struck the leaders of nomadic tribes" (Ivi: 519), and that of the "street". Whoever ventures into a way in solitude still has the feeling, in its «incalculable turnings and resolutions", of the power of "ancient directives over wandering hordes" (Ibidem). Who travels a street, on the other hand, does not need a guide, but simply submits to "the monotonous, fascinating, constantly unrolling band of asphalt" (Ibidem). As a synthesis of both experiences, that of street and way, condensed of two forms of terror (one for the unexpected and one for monotony), the labyrinth as a dialectical image experienced in language becomes the expression of a "monotonous wandering" (Ibidem). In its unstable ambivalence, this expression of the experience of the metropolitan labyrinth is destined to transform itself in divergent directions or in other images of an experience of the modern and post-modern city.

3. Perhaps only from a splitting to the extreme of the possibilities and destinies it implies, the form of a "monotonous wandering" as the very limit of the idea of a labyrinth, can we learn not only something about the present of our living, but also the destiny that it reserves us. For all of us there was the experience of a compulsion to stay inside one's own home, just at the moment when dwelling itself was deemed impossible, based on the lucid and disenchanted observations contained in the aphorism n.18 of the Minima moralia of Adorno. That experience that all of us, in varying degrees and forms, have had at the time of the lockdown of a physical constraint to stay at home precisely in the era in which dwelling's idea seemed to have become impossible or obsolete has imprinted - in my opinion - an acceleration to that idea of a generic city that Rem Koolhaas has conjugated with the term Junkspace (cfr. Koolhaas [2006]). All this with an ontological difference compared to that end of the century in which Koolhaas himself celebrated the generic city as a new beginning.

The generic city now no longer identifies itself only with some examples of megacities and with that tendency to demolish the boundaries of traditional cities with the affirmation in their place of ever-expanding metropolitan areas. Today, especially after what the pandemic meant for the overturning and reconfiguration of individual and collective habits, the relationship between the Junkspace of the physical, accumulative, and centerless metropolis and its virtual projection has been overturned. Hyperjunkspace where the network of urban relationships made of roads, paths, means of transport, chaotic traffic is nothing more than an epiphenomenon of another equally chaotic network, that of increasingly fragmented and multiple digital connections that substitute the internal space of everyone's life. Life hypermediated by electronic devices, life in front of a pure succession of screens: from the iPhone to the tablet, to the PC, to the TV and back, it realizes not in the sky but in the ethereal underground of telematic connections the idea of a generic city as "City freed from the slavery of the center, from the straitjacket of identity" (Ivi: 31). Relationships without quality, made mostly of ephemeral and tattered experiences that are condensed into emoticons and likes, contribute to realizing the idea of a city without history, "superficial" no longer "like the fence of a Hollywood film studio", but rather like a reality show that produces artificial identities with every television shoot. This phenomenon had been widely predicted by Koolhaas, insisting that now "vast sections of urban life are intertwined in cyberspace" (Ivi: 32 ). What changes now is that the front of this plot has directly become the cyberspace, while the socalled real life of the city, especially in the deserted and ghostly form experienced by each of us, is its 
reverse. Thus, if Koolhaas speaks of a "hallucination of normality" (Ivi: 33), now we must speak of a normality of hallucination: of a hallucinated and hallucinatory reality in which an evacuation of the public sphere is included, substituting it with neo-tribal collectives guided by uncontrolled emotional impulses. If $51 \%$ of the volume of the generic city is made up of atriums, like an eternal recurrence of an empty space, an even larger percentage of the virtual generic city is made up of access forms, empty to be filled in order to be admitted to forums, transversal associations, discussion groups, spaces reserved for transgression and the like. The form to be filled, basically identi$\mathrm{cal}$, is the antechamber, the waiting room for some promise of surrogate humanity.

In the end, we can agree with Koolhaas' thesis that the generic city bends into reality, it no longer represents the future, but reality itself. What Koolhaas forgets to mention is the saturated, non-porous character of this reality. No instance of liberation or emancipation in the proliferation of differences that attest to a logic of repetition in the Deleuzian sense: a logic of pure differences without identity, such as to ultimately precipitate into the monotony of the identical. Under this profile of its non-porous character where the virtual is the spectrum of the real, the generic city still describes the current time as the time of hell: a time that does not know or does not want to know the end. As Benjamin observes, completely organic at this time is "the acceleration of traffic and the speed of transmission of news» (Benjamin [2002a]: 66): the effort of a time directed to eliminate "all discontinuities and sudden ends" (ibidem), including death as a clean cut.

One might even wonder if it is still possible the experience of dying in an era in which the space of the generic city is only the reverse of the hyperphysics of the virtual Junkspace. Today, to die has become impossible: impossible, precisely by virtue of the spectrality of existence.

It could be argued at this point that to the extent that the hyperspace of the virtual generic city has assumed the infernal connotations of intrascendibility, a critical conception of Moder- nity capable of keeping alive the memory of the fractures that mark its origin as an epoch seems to have been defeated. I believe that recognizing this defeat is the only condition to take our reflection on the images of the contemporary city to the extreme, to the extreme of an idea that concerns the origin and the ontology of the city itself and, perhaps, ontology in general. To grasp this idea or image of the city as the possibly true, in the sense of a porous possibility that weaves the texture of reality with the force of an exigentia existendi, one must take a paradoxical gaze outside the city, the gaze of the stranger who approaches it after a long wandering, from the outside: from an outside that is intimate to it.

It is a question, as you will have understood, of assuming a Leibnizian gaze (of Benjamin's Leibniz and not of Deleuze): a gaze that captures and considers the city as a Monad, a gaze that represents a chance for thought and experience. From every perspective from which it is considered, the city as an exemplum of the monad confirms its identity and, at the same time, contains the differences captured in the different gazes who address it from different points. Moreover, it is Leibniz himself, in Monadology, who describes the representative activity of each monad and of the monads among themselves as a harmonization of identity and differences, in analogy to the image of the city that is constituted in the dialectic between its ontological identity and the differences perspectives it offers to individuals. In the diabolical time of the generic city, where the subject survives only as a virtual secession, the citymonad offers a space where each point constitutes a center: a polycentric space in the dialectical tension between identity and differences. That dialectic that, following the Sophist's Plato, is made possible only in language by crossing the threshold of otherness. By virtue of this dialectic, the image of the city as a Monad retains, not only as an archaic residue, the very experience of the labyrinth, with the promise that it contains happy passages within it: the continuity of a process in the heart of the tangle and in the intermittent nature of getting lost. Moreover, Leibniz himself speaks about the 
labyrinth of continuum. The omni-falsehood of the generic city whose time is the pure dispersion of the Junk-hyperspace is opposed by the omni truth of the city-monad as something of almost inconceivable for the present time. Yet something of which fragments are experienced and sparks are caught, sparks of thought and experience in a close interpenetration of interior and exterior spaces. Inasmuch as it is possible to grasp it with a paradoxically both external and internal gaze, this city-monad has the truth within it. Thus, for this dialectical image of city, the true has no windows as one of the most esoteric passages of the Passagenwerk states:

The true has no windows. Nowhere does the true look out to the universe. And the interest of the panorama is in seeing the true city. "The city in the bottle" - the city indoors. What is found within the windowless house is the true. One such windowless house is the theater; hence the eternal pleasure it affords. Hence. also, the pleasure taken in those windowless rotundas, the panoramas. (Benjamin [2002a]: 840)

Listening to this passage carefully, the dialectical image of the city as a monad becomes theatrum veritatis, where the conscience after its Hamletic wandering still Hamletically ${ }^{4}$ finds itself, in that knowing which has the Wittgesteinian characteristics of an übersichtliche Darstellung, which Alexandra Dias Fortes has rightly proposed to translate as a "panoramic presentation" (cfr. Dias Fortes [2021]). And here the circle can perhaps be closed.

\section{REFERENCES}

Benjamin, W., 2002a: The Arcades Project, transl. by $\mathrm{H}$. Eiland and K. McLaughlin, The Belknap Press of Harvard University Press, Cambridge, Mass., and London, England.

Benjamin, W., 2002b: Berlin Childhood around 1900, in Id., Selected Writings, Vol. 3, 1935-

\footnotetext{
${ }^{4}$ About this reference to the figure of Hamlet see Desideri [2019].
}

1938, edited by H. Eiland and M. W. Jennings, The Belknap Press of Harvard University Press, Cambridge, Mass., and London, England.

Desideri, F., 2019: Hamlet or Europe and the end of modern Trauerspiel. On some shakespearians motifs in Walter Benjamin, "Aisthesis" 12, pp. 117-126.

Desideri, F., 2020: Grenzwesen: espace, frontière, symbole chez Georg Simmel, in: Borsari, A., Antonioli, M. (eds), Georg Simmel et le champ architectural. Sociabilité urbaine, paysage et esthétisation $d u$ monde, Èditions Mimésis, Fano, pp. 155-168

Desideri, F., 2021: Dialektik im Stillstand. Prolegomeni ad un confronto tra Benjamin e Hegel, in Amato, P., Biuso, A.G., Bochicchio, V., Catena, M.T., Masi, F., Pinto, V., Russo, N., Venezia, S. (eds), Metafisica dell'immanenza. Scritti per Eugenio Mazzarella, Vol. I, Ontologia e storia, Mimesis, Milano-Udine, pp. 47-59.

Dias Fortes, A., 2021: Panoramic Presentation. Conceptual and Methodological Aspects, in Conceição, N., Ferraro, G., Fonseca, N., Dias Fortes, A., Molder, M.F. (eds), Conceptual Figures of Fragmentation and Reconfiguration, Universidade Nova de Lisboa Faculdade de Ciéncias Sociais e Humanas Instituto de Filosofia de NOVA, pp. 237-233

Koolhaas, R., 2006: Junkspace, ed. by G. Mastrigli, Quodlibet, Macerata [This Italian edition brings together three distinct essays by Koolhaas: Bigness or the problem of Large (1995), The Generic City (1995) and Junkspace (2001). For convenience we refer to this edition.]

Rilke, R. M., 1994: Poesie, ed. by G. Baioni, 2 Voll., Einaudi-Gallimard, Torino.

Simmel, G., 1995: Die Großstädte und das geistiges Leben, in G. Simmel, Gesamtausgabe, ed. by von O. Rammstedt, Bd. 7, Aufsätze und Abhandlungen 1901-1908, Bd. 1, pp. 116-131 [Simmel's essay originally appeared in "Jahrbuch der Gehestiftung", 1903, IX] 